\section{(6) OPEN ACCESS}

\title{
A proposal of new diagnostic pathway for fatal familial insomnia
}

\author{
A Krasnianski, ${ }^{1,2}$ P Sanchez Juan, ${ }^{3,4}$ Claudia Ponto, ${ }^{1}$ M Bartl, ${ }^{1}$ U Heinemann, \\ D Varges, ${ }^{1}$ W J Schulz-Schaeffer, ${ }^{5}$ H A Kretzschmar, ${ }^{6}$ । Zerr ${ }^{1}$
}

${ }^{1}$ Clinical Dementia Center and National Reference Center for TSE at Department of Neurology Georg-August University, Göttingen, Germany ${ }^{2}$ Department of Psychiatry, Psychosomatics and Psychotherapy Goethe University Frankfurt/M, Germany

${ }^{3}$ University Hospital Marqués de Valdecilla IFIMAV, Santander, Spain

${ }^{4}$ Centro de Investigación Biomédica en Red sobre Enfermedades

Neurodegenerativas,

Santander, Spain

${ }^{5}$ Department of

Neuropathology, Georg-August

University, Göttingen, Germany

${ }^{6}$ Department of

Neuropathology, Ludwig-

Maximilian University, Munich, Germany

\section{Correspondence to}

Professor Inga Zerr, National

TSE Reference Center,

Department of Neurology,

Georg-August-University,

Robert-Koch-Str. 40,

Göttingen D-37075, Germany; epicjd@med.uni-goettingen.de

Received 9 July 2013

Revised 8 October 2013

Accepted 18 October 2013

Published Online First

18 November 2013

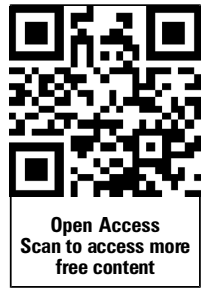

To cite: Krasnianski $A$, Sanchez Juan P, Ponto $C$ et al. I Neurol Neurosurg Psychiatry 2014:85: 654-659.

\section{ABSTRACT}

Background In absence of a positive family history, the diagnosis of fatal familial insomnia (FFI) might be difficult because of atypical clinical features and low sensitivity of diagnostic tests. FFI patients usually do not fulfil the established classification criteria for CreutzfeldtJakob disease (CJD); therefore, a prion disease is not always suspected.

Objective To propose an update of diagnostic pathway for the identification of patients for the analysis of D178-M129 mutation.

Design and methods Data on 41 German FFI patients were analysed. Clinical symptoms and signs, MRI, PET, SPECT, polysomnography, EEG and cerebrospinal fluid biomarkers were studied.

Results An algorithm was developed which correctly identified at least $81 \%$ of patients with the FFI diagnosis during early disease stages. It is based on the detection of organic sleep disturbances, either verified clinically or by a polysomnography, and a combination of vegetative and focal neurological signs and symptoms. Specificity of the approach was tested on three cohorts of patients (MM1 sporadic CJD patients, non-selected sporadic CJD and other neurodegenerative diseases).

Conclusions The proposed scheme may help to improve the clinical diagnosis of FFI. As the sensitivity of all diagnostic tests investigated but polysomnography is low in FFl, detailed clinical investigation is of special importance.

\section{INTRODUCTION}

The most common genetic form of prion disease worldwide is caused by a point mutation at codon 200 of the PRNP. ${ }^{1}$ In contrast, in Germany, the most frequently occurring mutation is located at the codon 178 of the PRNP (D178N mutation in coupling with methionine at codon 129: (D178N, $129 M))^{2}$ and leads subsequently to fatal familial insomnia (FFI). Clinicopathological features compatible with FFI have been described as early as in 1939 and $1963 .{ }^{3}{ }^{4}$ Lugaresi et $a l^{5}$ were the first to describe FFI in a patient with a family history of insomnia and autonomous disorders. Postmortem examination revealed marked atrophy of the anterior and dorsomedial thalamic nuclei. Later the disorder was classified as a prion disease and its transmissibility was confirmed in animal experiments. ${ }^{6}$ So far, a number of FFI patients with heterogeneous clinical phenotypes have been reported. ${ }^{7}$ The clinical phenotype in FFI seems also to depend on the M129V polymorphism. ${ }^{7-9}$ In most cases, the clinical diagnosis of FFI is hardly possible on the basis of the criteria established for sporadic Creutzfeldt-Jakob disease (sCJD) or familial CJD. ${ }^{10-13}$ Disease duration in FFI is as rule prolonged and CJD typical signs such as myoclonus are either absent or seen only very late in the disease course. Laboratory tests and technical investigations which are frequently positive in other prion diseases (14-3-3 proteins in cerebrospinal fluid (CSF), EEG, MRI) are usually normal or nonspecifically changed and so they do not provide any further clues to the diagnosis. ${ }^{714}$ Clinical criteria of FFI proposed several years ago are helpful in the diagnosis of FFI. ${ }^{15}{ }^{16}$ However, sensitivity and specificity of these criteria have to be determined in a context of differential diagnosis of rapid progressive dementia. Moreover, some new data have been collected since publication of the criteria, and the role of the codon 129 genotype in FFI phenotype has been recently demonstrated. ${ }^{9}$ The aim of the present study was to develop a scheme to support the clinical diagnosis of possible FFI and to provide a basis for the selection of patients who should be subjected to a PRNP analysis in the absence of clear family history for FFI. In addition, such a scheme might be helpful when PRNP analysis is not available for various reasons.

\section{DESIGN AND METHODS \\ Study design}

Patients with suspected prion disease were reported to the CJD Surveillance Unit in Göttingen and examined at the notifying hospital by the authors; the clinical data were collected as described previously. ${ }^{17}$ Data on sleep disturbances were obtained from anamnestical means (patients, their relatives, treating physicians), especially in the absence of polysomnography. CSF, blood samples and copies of the diagnostic tests (EEG, MRI, $\left[{ }^{18} \mathrm{~F}\right]$ FDG positron emission tomography (PET), ${ }^{123}$ I-IMP singlephoton emission CT (SPECT), polysomnography, laboratory tests) were taken. Because genetic testing was not available at the time as patients were enrolled into the study, they were classified according to established diagnostic criteria of sCJD. ${ }^{10}{ }^{11}$

\section{MRI and EEG findings}

The MRI images were classified as CJD-typical according to the established criteria. ${ }^{18}$ The EEGs were analysed according to established criteria. ${ }^{19}$

\section{Polysomnography}

Polysomnographic recordings were obtained at the notifying hospitals according to standard 
procedures; ${ }^{20}$ however, no specific analysis with respect to FFI diagnosis was done since FFI was not specifically suspected in most patients.

\section{PET and SPECT}

PET and SPECT were performed at the notifying hospitals as described previously. ${ }^{142122}$ Special attention was paid to thalamic hypometabolism.

\section{Neuropathological and molecular studies}

Western blot analysis and immunohistochemistry (in biopsied/ autopsied patients) and the analysis of PRNP were performed using standard methods. ${ }^{23-25}$

\section{Biochemical CSF analysis}

The 14-3-3 protein analysis was performed at least twice in each CSF sample as described previously. ${ }^{26}$

\section{Statistical analysis}

Significances (p) were tested by the SIGMASTAT 3.1 software (Systat Software Inc., Point Richmond, USA) using Student $\mathrm{t}$ test/Mann-Whitney rank sum test or $\chi^{2}$ test/Fisher exact test. A p value $<0.05$ was considered as statistically significant.

\section{RESULTS}

Study collective

From 1 June 1993 to 31 May 2005, 105 patients with a confirmed PRNP mutation were detected. Out of these patients, 32 were diagnosed with FFI. In addition, we included nine further FFI patients with available clinical data from the same families. Since in a few cases some data (eg, on the 14-3-3 test or MRI) were incomplete, some results were obtained on the basis of lower case numbers. In all, 28 patients were male and 13 were female (ratio $2.2: 1$ ). The median age at disease onset was 56 (range 23-73) years. The median disease duration was 11 (range 6-24) months. There were $20 \mathrm{MM}$ (12 male, eight female) and eight MV (seven male, one female) patients. In 13 patients, no M129V genotype was available, but the diagnosis had been confirmed by autopsy, and family history for (genetically proven) FFI was positive. The median age at disease onset in MM patients was 55 years (range 27-70), and the median disease duration was 10 months (range 6-21). The median age at disease onset in MV patients was 60 years (range 23-69) and the median disease duration was 19 months (range 10-24).

Disease onset and duration varied by codon M129V genotype (table 1), with a non-significantly earlier onset and significantly shorter duration in methionine homozygous (MM) patients $(p=0.007)$. Male gender was associated with an earlier age at

Table 1 Patient characteristics stratified by codon 129 genotype

\begin{tabular}{|c|c|c|c|c|c|c|c|}
\hline \multirow{2}{*}{$\begin{array}{l}\text { Codon } 129 \\
\text { polymorphism }\end{array}$} & \multirow[b]{2}{*}{ Sex } & \multirow[b]{2}{*}{$\mathrm{n}$} & \multicolumn{2}{|c|}{ Age at onset } & \multirow[b]{2}{*}{$\mathrm{n}$} & \multicolumn{2}{|c|}{$\begin{array}{l}\text { Duration of } \\
\text { illness (months) }\end{array}$} \\
\hline & & & Median & Range & & Median & Range \\
\hline \multirow[t]{3}{*}{ MM } & $\mathrm{m}$ & 12 & 53 & $27-67$ & 10 & 9 & $6-21$ \\
\hline & f & 8 & 57 & $50-70$ & 5 & 13 & $9-17$ \\
\hline & $\Sigma$ & 20 & 55 & $27-70$ & 15 & 10 & $6-21$ \\
\hline \multirow[t]{3}{*}{ MV } & $\mathrm{m}$ & 7 & 61 & $23-69$ & 5 & 15 & $10-24$ \\
\hline & $f$ & 1 & - & 48 & 1 & 23 & \\
\hline & $\Sigma$ & 8 & 60 & $23-69$ & 6 & 19 & $10-24$ \\
\hline
\end{tabular}

$\mathrm{f}$, female; $\mathrm{m}$, male. onset and a more rapid disease course. However, this association was not statistically significant.

\section{Clinical findings}

Data on the clinical findings have been previously published by the authors. ${ }^{9}$ The clinical features varied by M129V genotype (figure 1). The time of occurrence of symptoms and signs during disease course also varied depending on the M129V genotype (table 2).

\section{Neuropathological studies}

Autopsy was performed on 21 of our FFI patients. Overall, 20 of 21 patients showed FFI typical neuropathological findings with prominent thalamo-olivaric pathology. ${ }^{27}$ Severe astrocytic gliosis and nerve cell loss but weak spongiform changes were observed. Fine reticular $\mathrm{PrP}^{\mathrm{Sc}}$ deposits in the thalamus were only detectable with the PET blot method. ${ }^{25}$ This pattern resembles $\operatorname{PrP}^{\mathrm{Sc}}$ type 1 , although an electrophoretic mobility comparable with $\mathrm{PrP}^{\mathrm{Sc}}$ type 2 was described in FFI patients. ${ }^{28}$ Only one patient with confluent vacuoles (this without thalamo-olivaric pathology) showed perivacuolar $\operatorname{PrP}^{\mathrm{Sc}}$ deposits, which were detectable with conventional immunohistochemical staining methods.

\section{Diagnostic tests}

Detailed data on the diagnostic tests have been published previously. ${ }^{9}$ Almost all clinical and paraclinical tests revealed no or only slight non-specific changes. In FFI patients, the 14-3-3 test in the CSF, otherwise helpful in diagnosing prion diseases, was positive in two of 28 cases only. In one of them, inflammatory CSF changes (slight pleocytosis and oligoclonal bands) were detected. $^{12} 29$

\section{Family history of FFI}

Data on family history were available in 29 patients. Family history was negative in 10 of these patients (35\%) and positive in $19(65 \%)$.

\section{Development of the diagnostic pathway for FFI}

All possible combinations of symptoms and signs were tried and that with the highest sensitivity was selected. The weighting was performed by dividing the frequency of symptoms by week at appearance. The most common clinical symptoms and signs were grouped into three categories (A, B, C) (table 3). The first category comprises organic sleep disturbances (A), which were observed in almost all patients (96\%). The second category (B) consists of symptoms and signs frequently occurring in SCJD, which is the major differential diagnosis of FFI (CJD-like symptoms). ${ }^{12} 30$ The third category (C) comprises symptoms and signs which are typical for FFI, ${ }^{7}{ }^{31-34}$ and are not included in the diagnostic criteria of $\mathrm{sCJD}{ }^{10}$ To select the items required for the diagnosis of FFI, we weighted them in terms of their chronological occurrence (table 4). Some signs and symptoms were not evaluated either because they were observed in few cases only or, in most cases, because they could not be linked to a particular disease stage. In a second step, we divided the items into major and minor diagnostic parameters. The most important parameter was sleep disturbance, which occurred as the first symptom of FFI in all patients, except in one case. The minor parameters were selected and weighted according to their frequency and chronological occurrence (category C). Our aims were:

1. High sensitivity

2. High specificity 
Figure 1 Frequency of clinical symptoms and signs stratified by codon 129 genotype (\%).

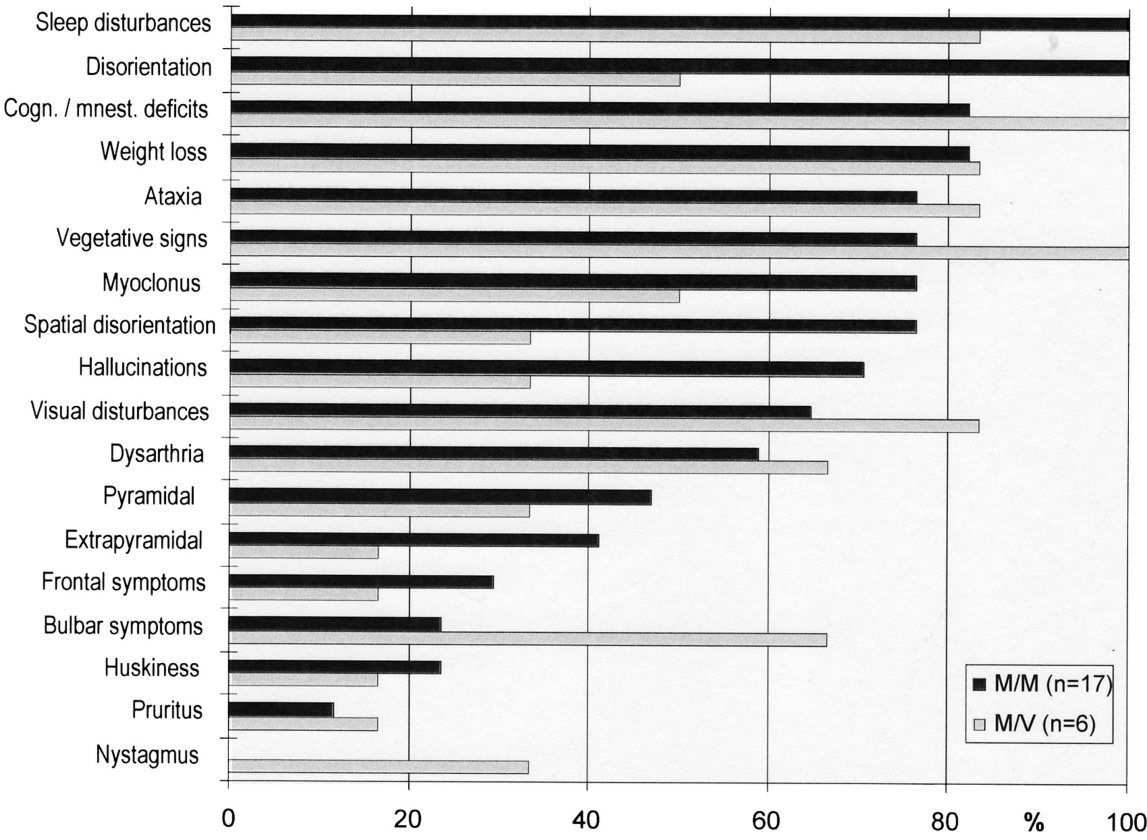

3. Reliable classification as FFI no later than in the middle of the disease course

4. Easy applicability (analogously to the CJD criteria).

In accordance with this scheme, all patients must have organic sleep disturbances (clinically apparent or by polysomnography). In addition, at least one symptom typical for FFI and two CJD-like symptoms are required for diagnosis of suspected FFI (figure 2). In these patients, a PRNP analysis is required as the subsequent diagnostic step.

\section{Verification of accuracy and applicability}

The proposed scheme reached a sensitivity of $91 \%$ in our original patient group. Based on their use, it was possible to establish the diagnosis of FFI within a median of 17 weeks (4.4 months) after disease onset. While a sensitivity of 100\% was found in our MV FFI patients, it was $88 \%$ in MM FFI patients. The median disease duration was 11 months, so the diagnosis based on the proposed criteria was established early in the disease course. We tested the applicability in an additional cohort of FFI patients who were seen in a prospective setting since June 2005 and were not included in the dataset for the scheme development. In these patients $(n=16)$, the proposed scheme correctly identified 13 of $16(81.3 \%)$ of the patients. Major reasons for failure were lack of autonomic disturbances and no data on weight loss or no weight loss.

To test specificity of our diagnostic approach for differentiation of FFI and sCJD, we applied our scheme to 40 randomly selected MM1 sCJD patients (24 women, 16 men; age range 54-86, median 68 years; median disease duration 4 , range 1-19 months) representing classical CJD. For randomisation, 40 subsequent MM1 patients diagnosed during the time period of the FFI recruitment for this study were taken. Only seven of these 40 sCJD patients fulfilled the criteria of FFI, so that the specificity within this group was high (83\%). This control group was selected because it represents the most frequent classical CJD type.

Loss of weight with a cut-off point of more than $10 \mathrm{~kg}$ during the last 6 months was observed in 5\% of sCJD patients in comparison with $83 \%$ in FFI $(p<0.001)$. Vegetative signs were found in only $33 \%$ of MM1 patients compared with $83 \%$ in FFI $(\mathrm{p}<0.001)$. Husky voice was noticed in none of MM1 patients, but in $22 \%$ of FFI patients $(p=0.005)$.

Table 2 Time of occurrence of symptoms/signs present both in codon $129 \mathrm{MM}$ and codon $129 \mathrm{MV}$ patients

\begin{tabular}{|c|c|c|c|c|c|c|}
\hline \multirow{2}{*}{$\begin{array}{l}\text { Symptom/sign } \\
\text { Genotype }\end{array}$} & \multicolumn{2}{|c|}{$\mathrm{N}$ patients $(\%)$} & \multicolumn{2}{|c|}{ Mean \pm SD (weeks) } & \multicolumn{2}{|c|}{ Median (weeks) } \\
\hline & MM $(n=17)$ & $M V(n=6)$ & MM $(n=17)$ & $M V(n=6)$ & MM $(n=17)$ & $M V(n=6)$ \\
\hline Vegetative & $13(77)$ & $6(100)$ & $4 \pm 0$ & $18.5 \pm 3$ & 0 & 23 \\
\hline Sleeping disturbances & $17(100)$ & $5(83)$ & $3 \pm 0$ & $15 \pm 0$ & 0 & 0 \\
\hline Bulbar & $5(29)$ & $5(83)$ & $19 \pm 0.5$ & $23 \pm 16$ & 11 & 20 \\
\hline Visual & $11(65)$ & $5(83)$ & $13 \pm 1$ & $6 \pm 2$ & 12 & 2 \\
\hline Cognitive/mnestic & $14(82)$ & $6(100)$ & $13 \pm 0$ & $16 \pm 0$ & 12 & 20 \\
\hline Hallucinations & $12(71)$ & $2(33)$ & $16 \pm 0$ & $57.5 \pm 19$ & 14 & 57.5 \\
\hline Spatial disorientation & $13(77)$ & $2(33)$ & $20 \pm 2$ & $38.5 \pm 1$ & 16 & 38.5 \\
\hline Ataxia & $13(77)$ & $6(100)$ & $21 \pm 4$ & $9 \pm 2$ & 20 & 4 \\
\hline Dysarthria & $10(59)$ & $4(67)$ & $21 \pm 0$ & $27 \pm 0.5$ & 20 & 28.5 \\
\hline Myoclonus & $13(77)$ & $3(50)$ & $16 \pm 1$ & $32 \pm 3.5$ & 21 & 32 \\
\hline Pyramidal & $8(47)$ & $2(33)$ & $29.5 \pm 5$ & $28 \pm 5$ & 26 & 28 \\
\hline
\end{tabular}


Table 3 Frequency of clinical symptoms and signs in fatal familial insomnia patients $(n=23)$

\begin{tabular}{|c|c|c|c|}
\hline & Symptoms and signs & $\mathrm{N}$ & $\%$ \\
\hline Category A & Organic sleep disturbances* & 22 & 96 \\
\hline \multirow[t]{20}{*}{ Category B } & Cognitive/mnestic deficits & 20 & 87 \\
\hline & Spatial disorientation & 15 & 65 \\
\hline & Psychiatric & 20 & 87 \\
\hline & Hallucinationst & 14 & 61 \\
\hline & Personality change & 13 & 57 \\
\hline & Depression & 5 & 22 \\
\hline & Anxiety & 4 & 17 \\
\hline & Aggressiveness & 2 & 9 \\
\hline & Disinhibition & 2 & 9 \\
\hline & Listlessness & 2 & 9 \\
\hline & Others $¥$, each & 1 & 4 \\
\hline & Ataxia & 19 & 83 \\
\hline & Myoclonus & 16 & 70 \\
\hline & Visual & 16 & 70 \\
\hline & Double vision & 12 & 52 \\
\hline & Blurred vision & 5 & 22 \\
\hline & Others§, each & 1 & 4 \\
\hline & Dysarthriaף & 14 & 61 \\
\hline & Pyramidal & 10 & 43 \\
\hline & Extrapyramidal ** & 8 & 35 \\
\hline \multirow[t]{14}{*}{ Category C } & Loss of weight & 19 & 83 \\
\hline & Vegetative signs & 19 & 83 \\
\hline & Hyperhidrosis & 13 & 57 \\
\hline & Newly diagnosed arterial hypertonia & 6 & 26 \\
\hline & Tachycardia & 4 & 17 \\
\hline & Obstipation & 3 & 13 \\
\hline & Hyperthermia & 2 & 9 \\
\hline & Otherstt, each & 1 & 4 \\
\hline & Bulbar symptoms & 10 & 43 \\
\hline & Husky voice & 5 & 22 \\
\hline & Dysphagia & 3 & 13 \\
\hline & Bulbar speech & 3 & 13 \\
\hline & Tongue fasciculation & 1 & 4 \\
\hline & Pruritus & 3 & 13 \\
\hline \multicolumn{4}{|c|}{$\begin{array}{l}\text { *Including polysomnography; insomnia, hypersomnia, restless sleep and sleep at } \\
\text { tOptical in } 14 \text { patients, additionally acoustic in two of them. } \\
\text { ‡Paranoia, fearfulness and rage to clean up. } \\
\text { §Seeing of flashes, poor vision, sliding field of vision and bad spatial vision. } \\
\text { १Pseudobulbar and cerebellar. } \\
{ }^{* *} \text { Nearly equally rigour, tremor and dystonia, mostly in combination. } \\
\text { ††Tachypnoea, arterial hypotonia, intolerance of warmth, goose bumps, cardiac } \\
\text { arrhythmia and abrogated day-night rhythm of blood pressure. }\end{array}$} \\
\hline
\end{tabular}

We also applied our algorithm to 40 randomly selected sCJD patients (23 MM, nine MV, eight VV genotype). There were 28 women, 12 men; age range was 41-81 years, median age was 73 years; and median disease duration was 10 months (range 2-28 months). For randomisation, 40 subsequent patients with excluded PRNP mutation diagnosed during the time period of the FFI recruitment for this study were taken. Only seven of these $40 \mathrm{sCJD}$ patients fulfilled the criteria of FFI, and so the specificity within this group was high (83\%).

Loss of weight with a cut-off point of more than $10 \mathrm{~kg}$ during the last 6 months was observed in $10 \%$ of these patients in comparison with $83 \%$ in FFI $(p<0.001)$. Vegetative signs were found in only $30 \%$ of non-selected sCJD patients compared with $83 \%$ in FFI $(\mathrm{p}<0.001)$. Husky voice was noticed in none of non-selected sCJD patients, but in $22 \%$ of FFI patients $(p=0.005)$. Thus, the results in this group were very similar to those in MM1 patients.

Moreover, we established a further control group consisting of all German CJD surveillance patients with neuropathologically proved diagnosis other than prion disease referred ante mortem to the surveillance centre as a potential prion disease, which
Table 4 Symptoms in fatal familial insomnia patients $(n=23)$ stratified by time of occurrence

\begin{tabular}{llll}
\hline Symptom/sign & Frequency* & $\begin{array}{l}\text { Time of } \\
\text { occurrence (d) }\end{array}$ & $\begin{array}{l}\text { Frequency } \\
\text { weighted by time }\end{array}$ \\
\hline $\begin{array}{llll}\text { Loss of weight } \\
\text { (<10 kg) }\end{array}$ & 19 & 14 & 1.357 \\
Husky voice & 5 & 14 & 0.357 \\
Psychiatric & 20 & 84 & 0.238 \\
Sleeping & 22 & 107 & 0.206 \\
disturbances & & & \\
Vegetative & 19 & 124 & 0.153 \\
Visual & 16 & 157 & 0.102 \\
Cognitive/mnestic & 20 & 207 & 0.097 \\
Frontal lobe signs & 2 & 22 & 0.091 \\
Myoclonus & 16 & 226 & 0.071 \\
Ataxia & 19 & 273 & 0.070 \\
Bulbar & 10 & 145 & 0.069 \\
Extrapyramidal & 5 & 78 & 0.064 \\
Spatial & 15 & 260 & 0.058 \\
disorientation & & & 0.054 \\
Dysarthria & 14 & 259 & 0.049 \\
Pyramidal & 10 & 205 & \\
\hline$*$ Number & & &
\end{tabular}

*Number of patients with positive symptom/sign.

included 30 patients (14 women, 16 men; age range 26-87, median 73.5 years; median disease duration 11.5 , range $1-$ 70.5 months). There were 15 patients with Alzheimer's disease (AD), four patients with inflammatory CNS diseases, two with both AD and Levy body disease (DLB), two with DLB, and one each with $\mathrm{AD}$ and congophil amyloidopathy, $\mathrm{AD}$ and vascular dementia, $\mathrm{AD}$ and unclear taupathy, congophil amyloidopathy, vascular dementia, autosomally dominant leukodystrophy, and metabolic CNS disease. In this patient group, only 20\% were identified by the algorithm as potential FFI cases. Loss of weight with a cut-off point of more than $10 \mathrm{~kg}$ during the last 6 months was observed in 3\% of neuropathologically confirmed non-prion disease patients compared with $83 \%$ in FFI $(\mathrm{p}<0.001)$. Vegetative signs were found in only $30 \%$ of non-prion disease patients in comparison with $83 \%$ in FFI $(p<0.001)$. Husky voice was absent in non-prion disease patients, but reported in $22 \%$ of FFI patients $(\mathrm{p}=0.012)$.

\section{DISCUSSION}

The aim of the present study was to develop a scheme for the clinical diagnosis of FFI. In addition, such a scheme might be also helpful when PRNP analysis is not available for various reasons.

As discussed previously and shown in table 2, there is a significant phenotypic variability between MM and MV genotypes. Myoclonus, spatial disorientation and hallucinations were more frequent in the MM patients. ${ }^{79}$ Bulbar disturbances and vegetative dysfunction were more common in MV FFI patients. Phenotypic differences between MV and MM FFI patients may be caused by different rates of $\operatorname{PrP}^{\mathrm{c}}$ to $\operatorname{PrP}^{\mathrm{Sc}}$ conversion. $^{35}$

Differently from our previous study, ${ }^{9}$ we analysed the clinical data in FFI patients in order to develop a scheme for early identification of patients who should be subjected to PRNP analysis. The rationale for this study is given in the Introduction section. To our knowledge, diagnostic criteria of FFI have been suggested twice. $^{15} 16$ They are based on data from 24 FFI patients. No 
Figure 2 Diagnostic algorithm for fatal familial insomnia.
A) Obligatory organic sleep disturbances. If not yet clinically apparent, a polysomnography has to be performed.

B) At least two of the following "CJD-like symptoms/signs"

1. Psychiatric*

2. Ataxia

3. Visual

4. Myoclonus

5. Cognitive/mnestic deficits

C) At least one of the following "relatively disease-specific symptoms/signs"

1. Loss of weight with a cułoff point of $>10 \mathrm{~kg}$ during the last 6 months

2. Vegetative**

3. Husky voice

\begin{abstract}
*Visual hallucinations, personality change, depression, anxiety, aggressiveness disinhibition, listlessness

**Hyperhidrosis, newly diagnosed arterial hypertonia, tachycardia, obstipation, hyperthermia
\end{abstract}

specificity or sensitivity of these criteria has been reported. They consist of six items and include clinical data, EEG and PET investigation. Since the availability of PET is limited, we intended to develop an easy and widely applicable scheme, which consists of three items and allows raising the suspicion of FFI by clinical means. The specificity of this approach was tested on two control groups with relevant differential diagnoses.

We attempted to establish an easily applicable scheme allowing reliable identification as a possible FFI no later than in the middle of the disease course. To make the attempt as precise as possible, we stratified the symptoms and signs of FFI by time of occurrence and their frequency. The scheme facilitates differentiation from the classical CJD, non-selected sCJD and non-CJD cases according to CJD criteria. ${ }^{10} 11$ However, differentiation from atypical sCJD subtypes may sometimes be more difficult.

A specificity of at least $80 \%$ could be reached for each of the groups. In contrast to FFI criteria (ICSD criteria and criteria proposed in the British Medical Bulletin ${ }^{15}$ ) which both require the presence of an autosomal dominant disease or a familial pattern, here we can select patients from families in which the FFI diagnosis is not established, as our studies showed that about a third of our patients did not fulfil this criterion. ${ }^{9}$ This fact might be explained by missing information about the presence of a neurodegenerative disorder by the family members or by occurrence of new mutations.

Interestingly, psychiatric symptoms were frequent in our FFI patients, and they are also common in sCJD. ${ }^{36}$ However, they are not a part of sCJD criteria, while we found them an important part of our FFI criteria.

Although the diagnosis of atypical subtypes of SCJD using the established criteria may fail, some diagnostic tests, such as MRI in the MV2 subtype and detection of the 14-3-3 proteins in MM2 and VV1 subtypes, are helpful in the sCJD diagnosis. ${ }^{37-39}$ The clinical diagnosis of FFI, by contrast, is solely based on the careful observation of the clinical course, and only polysomnography and, to some extent, PET may contribute to the FFI diagnosis before genetic testing is performed and a PRNP mutation is detected. ${ }^{14}$ All reports on FFI have emphasised the diagnostic importance of polysomnography in FFI, and this is also confirmed in our study. 7203440

\section{CONCLUSIONS}

Summarizing, we attempted to establish an easily applicable scheme allowing reliable classification as FFI no later than in the middle of the disease course. This facilitates differentiation both from the classical CJD and non-CJD cases initially classified as possible CJD as the most frequent classification in FFI patients according to CJD criteria. ${ }^{10}{ }^{11}$ Suspicion of FFI and consecutive order of appropriate genotyping by clinicians may be more frequent and could arise earlier, if updated, easily applicable clinical criteria are available. The scheme would also allow the clinical diagnosis in cases with no available genetic testing. A specificity of at least $80 \%$ and a sensitivity of $81.3 \%-91 \%$ could be reached. Early diagnosis of FFI might be important for early and sufficient counselling of patients and their relatives, also concerning the risk of inheritance, and potentially also for treatment studies. We hope that this attempt may improve the early recognition of this peculiar and rare prion disease.

Acknowledgements We thank Ms Bodemer and Ms Ciesielczyk for technical assistance. The assistance of Ms Ehrlich and Ms Schneider-Dominco is gratefully acknowledged.

Contributors AK: Conceptualisation of the study, analysis and interpretation of the data, drafting the manuscript, final approval. PSJ: Statistical analysis and interpretation of the data, drafting the manuscript, final approval. CP: Analysis and interpretation of the data, final approval. MB, UH and DV: Analysis and interpretation of the data, drafting the manuscript, final approval. WJS-S and HAK: Report of neuropathological findings, drafting the manuscript, final approval. IZ: Conceptualisation of the study, analysis and interpretation of the data, final approval. Statistical analysis was performed by PSJ.

Funding This work was supported by the Federal Ministry of Health (grant number 1369-341) and by European Commission (PRIORITY FP7-KBBE-2007-2A).

Competing interests All authors disclose any actual or potential conflicts of interest. This includes any financial, personal or other relationships with other people/organisations within 3 years of beginning the work submitted that could inappropriately influence their work.

Ethics approval Any necessary ethics committee approval was secured for the study reported by the local ethic committee of the Medical University of Goettingen.

Provenance and peer review Not commissioned; externally peer reviewed.

Open Access This is an Open Access article distributed in accordance with the Creative Commons Attribution Non Commercial (CC BY-NC 3.0) license, which permits others to distribute, remix, adapt, build upon this work non-commercially, and license their derivative works on different terms, provided the original work is properly cited and the use is non-commercial. See: http://creativecommons.org/ licenses/by-nc/3.0/ 


\section{REFERENCES}

1 Kovács GG, Puopolo M, Ladogana A, et al. Genetic prion disease: the EUROCJD experience. Hum Genet 2005;118:166-74.

2 Windl 0, Giese A, Schulz-Schaeffer W, et al. Molecular genetics of human prion diseases in Germany. Hum Genet 1999:105:244-52.

3 Stern K. Severe dementia associated with bilateral symmetrical degeneration of the thalamus. Brain 1939:62:157-71.

4 Garcin R, Brion S, Khochneviss A. Le syndrome de Creutzfeldt-Jakob et les syndromes cortico-striés de presenium (á l'ocassion de 5 observation anatomo-cliniques). Revue Neurologique 1963;109:419-41.

5 Lugaresi E, Medori R, Montagna P, et al. Fatal familial insomnia and dysautonomia with selective degeneration of thalamic nuclei. N Engl J Med 1986;315: 997-1003.

6 Telling GC, Parchi P, DeArmond SJ, et al. Evidence for the conformation of the pathologic isoform of the prion protein enciphering and propagating prion diversity [see comments]. Science 1996;274:2079-82.

7 Zarranz JJ, Digon A, Atares B, et al. Phenotypic variability in familial prion diseases due to the D178N mutation. J Neurol Neurosurg Psychiatry 2005:76:1491-6.

8 Montagna $P$, Cortelli $P$, Avoni $P$, et al. Clinical features of fatal familial insomnia: phenotypic variability in relation to a polymorphism at codon 129 of the prion protein gene. Brain Pathol 1998;8:515-20.

9 Krasnianski A, Bartl M, Sanchez-Juan PJ, et al. Fatal familial insomnia: clinical features and early identification. Ann Neurol 2008;63:658-61.

10 WHO. Human transmissible spongiform encephalopathies. Wkly Epidemiol Rec 1998:47:361-5.

11 Zerr I, Pocchiari M, Collins S, et al. Analysis of EEG and CSF 14-3-3 proteins as aids to the diagnosis of Creutzfeldt-Jakob disease. Neurology 2000;55:811-15.

12 Zerr I, Poser S. Clinical diagnosis and differential diagnosis of CJD and VCJD. With special emphasis on laboratory tests. APMIS 2002;110:88-98.

13 Appleby BS, Appleby KK, Hall RC, et al. D178N, 129Val and N171S, 129Val genotype in a family with Creutzfeldt-Jakob disease. Dement Geriatr Cogn Disord 2010;30:424-31.

14 Cortelli $P$, Perani $D$, Montagna $P$, et al. Pre-symptomatic diagnosis in fatal familial insomnia: serial neurophysiological and 18FDG-PET studies. Brain 2006;129:668-75.

15 Gambetti $\mathrm{P}$, Petersen $\mathrm{R}$, Monari $\mathrm{L}$, et al. Fatal familial insomnia and the widening spectrum of prion diseases. Br Med Bull 1993;49:980-94

16 Association ASD. Fatal Familial Insomnia (337.9). Rochester, USA, 2001.

17 Heinemann U, Krasnianski A, Meissner B, et al. Creutzfeldt-Jakob disease in Germany: a prospective 12-year surveillance. Brain 2007:130(Pt 5):1350-9.

18 Zerr I, Kallenberg K, Summers DM, et al. Updated clinical diagnostic criteria for sporadic Creutzfeldt-Jakob disease. Brain 2009;132:2659-68.

19 Steinhoff BJ, Räcker S, Herrendorf G, et al. Accuracy and reliability of periodic sharp wave complexes in Creutzfeldt-Jakob disease. Arch Neurol 1996:53:162-6.

20 Sforza E, Montagna $\mathrm{P}$, Tinuper $\mathrm{P}$, et al. Sleep-wake cycle abnormalities in fatal familial insomnia. Evidence of the role of the thalamus in sleep regulation. Electroencephalogr Clin Neurophysiol 1995;94:398-405.

21 Matsuda M, Tabata K, Hattori T, et al. Brain SPECT with 123I-IMP for the early diagnosis of Creutzfeldt-Jakob disease. J Neuro/ Sci 2001;183:5-12.
22 Henkel $\mathrm{K}$, Zerr I, Hertel A, et al. Positron emission tomography with $\left[{ }^{18} \mathrm{~F}\right] \mathrm{FDG}$ in the diagnosis of Creutzfeldt-Jakob disease (CJD). J Neurol 2002;249:699-705.

23 Kitamoto T, Shin RW, Doh-Ura K, et al. Abnormal isoform of prion protein accumulates in the synaptic structures of the central nervous system in patients with Creutzfeldt-Jakob disease. Am J Pathol 1992:140:1285-94.

24 Kretzschmar HA, Ironside JW, DeArmond SJ, et al. Diagnostic criteria for sporadic Creutzfeldt-Jakob disease. Arch Neurol 1996:53:913-20.

25 Schulz-Schaeffer WJ, Tschoke S, Kranefuss N, et al. The paraffin-embedded tissue blot detects $\operatorname{Pr} P(S c)$ early in the incubation time in prion diseases. Am J Pathol 2000;156:51-6.

26 Zerr I, Bodemer M, Gefeller 0, et al. Detection of 14-3-3 protein in the cerebrospinal fluid supports the diagnosis of Creutzfeldt-Jakob disease. Ann Neurol 1998;43:32-40

27 Reder AT, Mednick AS, Brown P, et al. Clinical and genetic studies of fatal familial insomnia. Neurology 1995;45:1068-75.

28 Parchi P, Petersen RB, Chen SG, et al. Molecular pathology of fatal familial insomnia. Brain Pathol 1998:8:539-48.

29 Sanchez-Juan P, Green A, Ladogana A, et al. CSF tests in the differential diagnosis of Creutzfeldt-Jakob disease. Neurology 2006;67:637-43.

30 Parchi P, Giese A, Capellari S, et al. Classification of sporadic Creutzfeldt-Jakob disease based on molecular and phenotypic analysis of 300 subjects. Ann Neurol 1999;46:224-33

31 McLean CA, Storey E, Gardner RJ, et al. The D178N (cis-129M) "fatal familial insomnia" mutation associated with diverse clinicopathologic phenotypes in an Australian kindred. Neurology 1997:49:552-8.

32 Padovani A, D'Alessandro M, Parchi $P$, et al. Fatal familial insomnia in a new Italian kindred. Neurology 1998;51:1491-4.

33 Almer $\mathrm{G}$, Hainfellner JA, Brucke $T$, et al. Fatal familial insomnia: a new Austrian family. Brain 1999;122(Pt 1):5-16.

34 Gambetti P, Parchi P, Chen SG. Hereditary Creutzfeldt-Jakob disease and fatal familial insomnia. Clin Lab Med 2003;23:43-64.

35 Gambetti $\mathrm{P}$, Parchi $\mathrm{P}$, Petersen RB, et al. Fatal familial insomnia and familial Creutzfeldt-Jakob disease: clinical, pathological and molecular features. Brain-Pathol 1995:5:43-51.

36 Wall CA, Rummans TA, Aksamit AJ, et al. Psychiatric manifestations of Creutzfeldt-Jakob disease: a 25-year analysis. J Neuropsychiatry Clin Neurosci 2005;17:489-95.

37 Meissner B, Westner I, Kallenberg K, et al. Sporadic Creutzfeldt-Jakob disease: clinical and diagnostic characteristics of the rare VV1 type. Neurology 2005;65:1544-50.

38 Krasnianski A, Meissner B, Schulz-Schaeffer W, et al. Clinical features and diagnosis of the MM2 cortical subtype of sporadic Creutzfeldt-Jakob disease. Arch Neurol 2006:63:876-80

39 Krasnianski A, Schulz-Schaeffer WJ, Kallenberg K, et al. Clinical findings and diagnostic tests in the MV-2 subtype of sporadic CJD. Brain 2006;129:2288-96.

40 Manetto V, Medori R, Cortelli $\mathrm{P}$, et al. Fatal familial insomnia: clinical and pathologic study of five new cases. Neurology 1992;42:312-19. 